\title{
Dietary açai attenuates hepatic steatosis via adiponectin-mediated effects on lipid metabolism in high-fat diet mice
}

\author{
Joyce Ferreira da Costa Guerra a, Poliane Silva Maciel ${ }^{b}$, \\ Isabel Cristina Mallosto Emerich de Abreu ${ }^{b}$, Renata Rebeca Pereira ${ }^{a, c}$, \\ Maisa Silva ${ }^{d}$, Leandro de Morais Cardoso ${ }^{e}$, \\ Helena Maria Pinheiro-Sant'Ana ${ }^{f}$, Wanderson Geraldo de Lima ${ }^{c}$, \\ Marcelo Estáquio Silva ${ }^{9}$, Maria Lúcia Pedrosa ${ }^{a, c, *}$ \\ a Biological Research Center, Federal University of Ouro Preto, Ouro Preto, MG, Brazil \\ b School of Nutrition, Federal University of Ouro Preto, Ouro Preto, MG, Brazil \\ ${ }^{c}$ Department of Biological Sciences, Federal University of Ouro Preto, Ouro Preto, MG, Brazil \\ d Department of Basic Health, Federal University of Juiz de Fora, Governador Valadares Campus, Governador Valadares, MG, Brazil \\ e Department of Nutrition, Federal University of Juiz de Fora, Governador Valadares Campus, Governador Valadares, MG, Brazil \\ ${ }^{\mathrm{f}}$ Department of Nutrition and Health, Federal University of Viçosa, Viçosa, MG, Brazil \\ g Department of Food Science, Federal University of Ouro Preto, Ouro Preto, MG, Brazil
}

\section{A R T I C L E I N F O}

Article history:

Received 9 December 2014

Received in revised form 16 January

2015

Accepted 20 January 2015

Available online 13 February 2015

Keywords:

Euterpe oleracea mart

Anthocyanins

Nonalcoholic fatty liver disease

Insulin resistance

Adipokines

Peroxisome proliferator-activated

receptor $\alpha$

\begin{abstract}
A B S T R A C T
Polyphenols, especially anthocyanins, have been considered promising for the prevention of nonalcoholic fatty liver disease (NAFLD). This study investigated whether açai (Euterpe oleracea Mart.), a source of anthocyanins and recognized as one of the new "superfruits", could alleviate high-fat diet (HFD)-induced NAFLD in mice. In HFD mice, aqueous açai extract (AAE) administration $(3 \mathrm{~g} / \mathrm{kg}$ ) for six weeks improved insulin resistance index and increased adiponectin mRNA expression in adipose tissue and serum levels. Furthermore, AAE decreased the total liver triacylglycerol content and attenuated HFD-induced hepatic steatosis. This reduced hepatic lipid content was associated with AAE-mediated up-regulation of genes involved in adiponectin signaling, including adiponectin receptor 2, PPAR- $\alpha$, and its target gene, carnitine palmitoyltransferase. Thus, dietary açai can protect liver from steatosis through its enhancement of adiponectin levels, improvement of insulin sensitivity, and increase in PPAR- $\alpha$-mediated fatty acid oxidation.
\end{abstract}

(c) 2015 Elsevier Ltd. All rights reserved.

* Corresponding author. Biological Research Center, Federal University of Ouro Preto, Ouro Preto, MG, Brazil. Tel.: +55 3135591696; fax: +55 3135591696.

E-mail address: lpedrosa@nupeb.ufop.br (M.L. Pedrosa).

Abbreviations: ACC, acetyl coenzyme A carboxylase; AdipoR2, adiponectin receptor 2; ALT, alanine aminotransferase; AST, aspartate aminotransferase; CPT-1, carnitine palmitoyltransferase 1; C3G, cyanidin 3-glucoside; DPPH, 2,2-diphenyl-1-picrylhydrazil; FAS, fatty acid synthase; FAT, fatty acid translocase; FFA, free fatty acid; HOMA-IR, homeostasis model assessment of insulin resistance; IL-6, interleukin 6; IR, insulin resistance; NAFLD, nonalcoholic fatty liver disease; PPAR, peroxisome proliferator-activated receptor; SREBP-1c, sterol regulatory element-binding protein-1c; TG, triacylglycerol; TNF $\alpha$, tumor necrosis factor $\alpha$; Trolox, 6-hydroxy-2,5,7,8-tetramethylchroman-2carboxylic acid; UCP-2, uncoupling protein 2; WAT, white adipose tissue

Chemical compounds: Cyanidin 3-rutinoside (PubChem CID: 29231); Cyanidin 3-glucoside (PubChem CID: 197081).

http://dx.doi.org/10.1016/j.jff.2015.01.025

1756-4646/@ 2015 Elsevier Ltd. All rights reserved. 


\section{Introduction}

Nonalcoholic fatty liver disease (NAFLD) is a growing health problem and is currently the most common chronic liver disease. Accumulation of triacylglycerols (TG) in hepatocytes (steatosis) is the earliest and most prominent change in NAFLD. This increases the vulnerability of the liver to oxidative and inflammatory insults that can potentially contribute to progression to more advanced stages of hepatic damage, such as steatohepatitis, fibrosis, and cirrhosis (Browning \& Horton, 2004; Neuschwander-Tetri \& Caldwell, 2003; Wang, Wei, \& Pagliassotti, 2006).

Multiple metabolic pathways are involved in the development of hepatic steatosis, including enhanced non-esterified fatty acid release from white adipose tissue (WAT), increased de novo fatty acid synthesis, and decreased $\beta$-oxidation (Postic \& Girard, 2008). Hepatic lipid homeostasis is coordinated and controlled by key transcriptional regulators such as sterol regulatory element binding protein-1c (SREBP-1c) and peroxisome proliferator-activated receptor $\alpha$ (PPAR- $\alpha$ ). SREBP-1c is a transcription factor that regulates fatty acid biosynthesis by increasing the transcription of key enzymes, including fatty acid synthase (FAS) and acetyl-CoA carboxylase (ACC). The expression of this transcription factor is constitutively elevated in insulin-resistant individuals. This increases lipogenesis, which leads to TG accumulation in the liver and to the development of hepatic steatosis (Shimomura, Bashmakov, \& Horton, 1999). PPAR- $\alpha$ is mainly expressed in the liver and is a ligandactivated transcription factor important in the regulation of several key enzymes involved in fatty acid oxidation (Stienstra, Duval, Muller, \& Kersten, 2007).

NAFLD is strongly associated with insulin resistance and is estimated to occur in $70-100 \%$ of obese individuals (Farrell \& Larter, 2006). For this reason, it can be considered to be the hepatic manifestation of metabolic syndrome (Marchesini et al., 2001; Ong \& Younossi, 2007). Bioactive proteins secreted from WAT, collectively known as adipokines, have been implicated in modulating insulin sensitivity. Adiponectin is an adipokine that acts as an insulin sensitizer, stimulating fatty acid oxidation in liver and muscle. Furthermore, adiponectin was also effective in ameliorating the hepatomegaly, steatosis, and alanine aminotransferase abnormalities associated with NAFLD in mice (Xu et al., 2003). Thus, increased adiponectin levels are strongly correlated with the prevention of fatty liver disease.

Diet can either increase or decrease the risk for NAFLD and dietary therapies for the prevention of the earliest stage of this condition, liver steatosis, have therefore attracted considerable attention and has become an important area in nutrition and food research. This is attributed, in part, to the great diversity of bioactive non-nutrient compounds present in foods. Among these compounds, anthocyanins have been considered particularly promising for the prevention of NAFLD (Valenti et al., 2013). The ability of anthocyanins to reduce the risk of chronic diseases has been linked to their antioxidant capacity; however, recent findings have suggested that anthocyanins may exert their beneficial effects by interacting with a wide range of molecular targets of intracellular signaling machinery (Dragano et al., 2013; Fernandes, Faria, Calhau, de Freitas, \& Mateus, 2014) including key transcription factors that coor- dinate lipid metabolism, such as PPAR- $\alpha$ (Jia et al., 2013) and SREBP-1c (Hwang et al., 2011). Although there are many reports about the health benefits of anthocyanin-rich extracts, studies to test whether physiologically relevant doses of anthocyanins could exert such effects are lacking.

Açai (Euterpe oleracea Mart.) is a fruit from the Amazon region that has gained international popularity due to its high content of polyphenols, predominantly anthocyanins, proanthocyanidins, and other flavonoids. Given its phytochemical composition and the beneficial effects associated with its consumption, this fruit has a potential role as a functional food (Marcason, 2009; Schauss, Wu, Prior, Ou, Huang et al., 2006). In this respect, its most significant properties include the improvement of the oxidant/antioxidant balance (Guerra, Magalhaes, Costa, Silva, \& Pedrosa, 2011) and hypocholesterolemic (de Souza, Silva, Silva, Oliveira Rde, \& Pedrosa, 2010), anti-atherogenic, and anti-inflammatory effects (Xie et al., 2011). A pilot study on overweight individuals demonstrated that ingestion of açai pulp for one month had beneficial effects on glucose homeostasis and serum markers of metabolic risk (Udani, Singh, Singh, \& Barrett, 2011). Additionally, rat dietary supplementation with $2 \%$ açai pulp produced a hypocholesterolemic effect mediated by the enhanced expression of the ATP-binding cassette, subfamily G transporters 5 and 8 , and low-density lipoprotein receptor genes (de Souza et al., 2012). Considering its phytochemical composition and potentially beneficial effects on metabolic disorders, we hypothesized that açai would ameliorate NAFLD and its complications in mice on a high-fat diet (HFD). Moreover, the present study aimed to investigate whether the use of physiologically relevant amounts of anthocyanins from açai, that closely mimic their intake in human diet, could exert biological effects as well as the relevant regulatory pathways underlying these effects.

\section{Materials and methods}

\subsection{Açai preparation and nutrient composition}

Pasteurized frozen açai pulp without colorants or preservatives was obtained from Icefruit Comércio de Alimentos Ltda. (Tatuí, São Paulo, Brazil). This commercial pulp was obtained by macerating the açai pericarp and mixing it with water to obtain a solid content of 11-14\% (medium grade). The pulp was stored at $-20^{\circ} \mathrm{C}$ until use, at which time it was thawed and filtered through Whatman no. 1 filter paper (Maidstone, England). The resultant açai aqueous extract (AAE) was directly administered to animals by oral gavage. The moisture content of AAE was $98 \%$; and each $100 \mathrm{~g}$ of dry weight had $2.9 \mathrm{~g}$ of total fat, $7.2 \mathrm{~g}$ of protein, $68.3 \mathrm{~g}$ of total carbohydrate, and $3.6 \mathrm{~g}$ of fiber, as determined according to the Normas Analíticas do Instituto Adolfo Lutz (2008).

\subsection{Phytochemical composition and antioxidant activity of AAE}

The Folin-Ciocalteu method was used to determine the total phenolic content as described by George, Brat, Alter, and Amiot 
(2005). Gallic acid was used as a standard for the calibration curve. The total amount of phenolic compounds was expressed in milligrams of gallic acid equivalents (GAE) per $100 \mathrm{~g}$ of AAE.

Total flavonoid content of AAE was determined by using the aluminium chloride colorimetric method as described by Hossain and Rahman (2011). Quercetin was used as a standard for the calibration curve.

Identification and quantification of anthocyanins cyanidin 3-O-glucoside and cyanidin 3-O-rutinoside from AAE were performed by HPLC-DAD (Shimadzu, SCL 10AT VP). Chromatographic conditions followed previously described methods (Gallori, Bilia, Bergonzi, Barbosa, \& Vincieri, 2004; Schauss, Wu, Prior, Ou, Huang et al., 2006) with adaptations. Separations were conducted using a Phenomenex Gemini RP-18 $(5 \mu \mathrm{m}$; $250 \mathrm{~mm} \times 4.6 \mathrm{~mm}$ ) with a Phenomenex RP-18, $4 \times 3 \mathrm{~mm}$ guard column. The mobile phase consisted of $89 \%$ ultrapure water acidified with formic acid to $\mathrm{pH} 2.0$ and 11\% acetonitrile (v/v) (line A) and 100\% acetonitrile (line B) run at $1 \mathrm{~mL} \cdot \mathrm{min}^{-1}$. The injection volume was $50 \mu \mathrm{L}$. The run time was $45 \mathrm{~min}$, and the chromatogram readings were taken at $520 \mathrm{~nm}$. The gradient at the mobile phase was: $0 \%$ B from 0 to $20 \mathrm{~min} ; 50 \% \mathrm{~B}$, a linear gradient, from 20 to $22 \mathrm{~min}$; $50 \% \mathrm{~B}$, from 22 to $27 \mathrm{~min} ; 0 \% \mathrm{~B}, \mathrm{a}$ linear gradient, from 27 to $29 \mathrm{~min}$; and 0\% B from 29 to $45 \mathrm{~min}$. AAE was filtered through a Millipore Nylon membrane, $0.45 \mu \mathrm{m}$. Identification of the anthocyanins was based on retention times and UV-Vis spectra of cyanidin-3-O-glucoside and cyanidin3-O-rutinoside commercial standards (Sigma-Aldrich, St. Louis, MO, USA). The quantification was performed by comparing peak areas with that obtained in the analytical curve constructed from injection, in duplicate, of six different concentrations of standard solutions (cyanidin-3-O-glucoside: 0.01-2.40 $\mu \mathrm{g}$, $\mathrm{y}=3,996,555.72 \mathrm{x}-56,356.59, \mathrm{R}^{2}$ : 0.99; cyanidin-3-O-rutinoside: $0.01-3.55 \mu \mathrm{g}, \mathrm{y}=3,302,563.82 \mathrm{x}-57,350.62, \mathrm{R}^{2}$ : 0.99). The individual concentration of anthocyanins was expressed in $\mathrm{mg} / 100 \mathrm{~g}$.

The total anthocyanin content of AAE was determined by the differential $\mathrm{pH}$ method, as previously described by Guerra et al. (2011), and was expressed in mg of cyanidin-3-glucoside equivalents per $100 \mathrm{~g}$ of $\mathrm{AAE}$.

The antioxidant capacity was determined by the modified DPPH method (Brand-Williams, Cuvelier, \& Berset, 1995) which is based on the quantification of free radical-scavenging. A methanol solution containing $0.06 \mathrm{mM}$ DPPH was prepared. After adjusting the blank with methanol, an aliquot of $100 \mu \mathrm{L}$ of AAE extract were added to $3.9 \mathrm{~mL}$ of this solution. The mixture was homogenized and kept in the dark for $30 \mathrm{~min}$ at room temperature. Antioxidant activity was determined by the reduction in absorbance of the DPPH radical at $515 \mathrm{~nm}$. Trolox (6-hydroxy-2,5,7,8-tetramethylchroman-2-carboxylic acid) was used as an antioxidant standard and the results were expressed as Trolox equivalent antioxidant capacity ( $\mu \mathrm{M} \mathrm{TEAC/g).}$

\subsection{Animals and experimental design}

Male Swiss mice were obtained from the Laboratory of Experimental Nutrition at the School of Nutrition of the Federal University of Ouro Preto (UFOP). The mice were approximately 30 days old and weighed approximately $25 \mathrm{~g}$. They were housed in polypropylene cages with four animals per cage and
Table 1 - Compositions of the experimental diets $(\mathrm{g} / \mathrm{kg}$ diet).

\begin{tabular}{lcc} 
Ingredients & Diets & \\
\cline { 2 - 3 } & $\begin{array}{l}\text { AIN-93M } \\
\text { standard diet }\end{array}$ & $\begin{array}{c}\text { High-fat } \\
\text { diet }\end{array}$ \\
\hline Casein & 140.0 & 190.0 \\
Cornstarch & 467.5 & 87.5 \\
Sucrose & 100 & 100 \\
Maltodextrin & 155 & 155 \\
Soy bean oil & 40.0 & 40.0 \\
Lard & - & 320 \\
Cholesterol & & 10 \\
Choline & 2.5 & 2.5 \\
Mineral mix & 35.0 & 35.0 \\
Vitamin mix & & 10.0 \\
Cellulose & 10.0 & 50.0 \\
Energy content g (kcal/kg) & 50.0 & 5400 \\
Carbohydrate (\% energy) & 3800 & 26 \\
Protein (\% energy) & 76 & 14 \\
Fat (\% calories) & 14 & 60 \\
\hline a Mineral and bitamin mixture as recommended by the AIN-93M \\
$\quad$ rodent diet. & 10 & \\
c Conversion factors: protein, 4 kcal/g; fat, 9 kcal/g; sugars, 4 kcal/g.
\end{tabular}

maintained in a controlled temperature, light, and humidity environment, with food and water provided ad libitum. Animal procedures were approved by the Ethics Committee in Animal Research of the UFOP (Protocol No. 2011/63).

Initially, 32 mice were divided into two experimental groups; the $\mathrm{C}$ group were fed the AIN-93M standard diet (Reeves, Nielsen, \& Fahey, 1993) and the HF group received an HFD (32\% lard and $1 \%$ cholesterol). The compositions of these experimental diets are described in Table 1. After six weeks, the groups were subdivided into groups $C$ and $C A$ (standard diet), and HF and HFA (HFD). The CA and HFA groups were treated with AAE, administered as a single daily dose $(3 \mathrm{~g} / \mathrm{kg})$ via gavage during the light phase. The $C$ and $\mathrm{HF}$ groups received an equal volume of distilled water. After 12 weeks of these treatments, the mice were fasted for $12 \mathrm{~h}$, anesthetized with isoflurane, and euthanized by exsanguination. Blood was collected in polypropylene tubes and centrifuged at $3000 \times \mathrm{g}$ for $15 \mathrm{~min}$. Serum was then removed and stored at $-80^{\circ} \mathrm{C}$. The liver and the epididymal, mesenteric, and retroperitoneal WAT were collected and weighed. The small hepatic lobe was stored in buffered formalin for histopathological analysis and the rest of the liver was submerged in liquid nitrogen and immediately stored at $-80^{\circ} \mathrm{C}$.

\subsection{Biochemical analysis}

Serum concentrations of glucose and the activities of alanine aminotransferase (ALT) and aspartate aminotransferase (AST) were determined enzymatically using kits from Labtest (Lagoa Santa, MG, Brazil). Serum insulin and adiponectin levels were quantified using enzyme-linked immunosorbent assays (ELISA) obtained from Crystal Chem (Downers Grove, IL, USA), and Millipore (Billerica, MA, USA), respectively.

The homeostasis model assessment of insulin resistance (HOMA-IR) was calculated using the final blood glucose and 
insulin determinations. This method is widely used to estimate insulin resistance in humans and animal models. The following formula was applied (Matthews et al., 1985):

$$
\begin{aligned}
\text { HOMA-IR }= & \text { fasting glucose }(\mathrm{mmol} / \mathrm{L}) \\
& \times \text { fasting insulin }(\mathrm{mU} / \mathrm{L}) / 22.5
\end{aligned}
$$

\subsection{Liver tissue analyses}

Hepatic lipids were extracted from liver tissue using a chloroform/methanol solution (2:1, vol/vol), as described by Folch, Lees, and Sloane Stanley (1957). Total hepatic lipids were obtained by solvent evaporation. The dried lipid residue was dissolved in $1 \mathrm{~mL}$ isopropanol, and TG was analyzed using a commercial kit from Labtest.

\subsection{Histological analyses}

The liver tissue samples were fixed in $10 \%$ buffered formalin and embedded in paraffin. Tissue sections $(5 \mu \mathrm{m})$ were cut with a microtome (Leica, Germany) and mounted on microscope slides. The slides were then stained with hematoxylin and eosin (H\&E) and photographed at $400 \times$ magnification. A semiquantitative scoring system was used to assess the severity of hepatic steatosis in 10 microscopic fields examined as described previously (Albano et al., 2005). In brief, steatosis was graded from 1-3 depending on the percentage of hepatocytes that contained fat; grade 1 was assigned if $<33 \%$ of hepatocytes contained fat, grade 2 if $33-66 \%$ contained fat, and grade 3 if $>66 \%$ contained fat.

\subsection{Real-time quantitative reverse transcription- polymerase chain reaction (RT-PCR) assay}

Total RNA was isolated from liver and epididymal WAT using the RNAgents Total RNA Isolation System (Promega Corporation, Madison, WI, USA) according to the manufacturer's instructions. cDNA was synthesized from $2 \mu \mathrm{g}$ of total RNA with random primers using the High-Capacity cDNA Reverse Transcription Kit (Applied Biosystems, Foster City, CA, USA) and following the manufacturer's recommendations. Real-time PCR was performed using the Power SYBR® Green PCR Master Mix reagent (Applied Biosystems).

The following primer sequences are used: 18S rRNA: 5'GTAAGTGCGGGTCATAAG-3'(forward); 5'-CCATCCAATCG GTAGTAGC-3' (reverse); ACC1: 5'-GCTAAACCAGCACTCCCGAT3'(forward); 5'-GTATCTGAGCTGACGGAGGC-3' (reverse); Adiponectin: 5'-CCCAGTCATGCCGAAGATGA-3'(forward); 5'CACAAGTTCCCTTGGGTGGA-3' (reverse); ADIPO- R2: 5'GTGTGGAGGACCATCCCTTG-3'(forward); 5'-AGTGCGTGC TAACAACTCCA-3' (reverse); FAS: 5'-GGAGGTGGTGATAGCC GGTAT-3'(forward); 5'-TGGGTAATCCATAGAGCCCAG-3' (reverse); CPT1- $\alpha$ : 5'-CACCAACGGGCTCATCTTCT-3'(forward); 5'AGGCACTCTCACAGAGGGAT-3' (reverse); FAT/CD36: 5'AATTAGTAGAACCGGGCCAC-3'(forward); 5'-CCAACTCCCA GGTACAATCA-3' (reverse); PPAR- $\alpha$ : 5'-ACACCTTCCTCTT CCCAAAGC-3'(forward); 5'-TGATGACCTGTACGAGCTGC-3' (reverse); SRBP1-c: 5'-GCGGTTGGCACAGAGCTT-3'(forward); 5'GGACTTGCTCCTGCCATCAG-3' (reverse); UCP-2: 5'-CCAAC
AGCCACTGTGAAGTT-3'(forward); 5'-GCACTAGCCCTTGACTC TCC-3' (reverse). The reactions were performed under the following conditions: $50{ }^{\circ} \mathrm{C}$ for $2 \mathrm{~min}, 95^{\circ} \mathrm{C}$ for $10 \mathrm{~min}$, and then 40 cycles of $95^{\circ} \mathrm{C}$ for $15 \mathrm{~s}$ (denaturation) and $60^{\circ} \mathrm{C}$ for $1 \mathrm{~min}$ (primer annealing and product extension). The specificity of the products obtained was confirmed by analysis of the amplified product dissociation curves. The data obtained were analyzed using the comparative $\mathrm{C}_{\mathrm{q}}$ method. Target gene expression was determined relative to the expression of the endogenous $18 \mathrm{~S}$ ribosomal RNA gene. All analyses were performed in triplicate.

\subsection{Statistical analysis}

The normality of the data was tested using the KolmogorovSmirnov test. The data were analyzed by one-way analysis of variance (ANOVA) followed by the Bonferroni post hoc test or the Kruskal-Wallis test and the Dunn post-test (for parametric and non-parametric data, respectively). Data were expressed as mean \pm standard error of the mean (SEM) or as medians and interquartile ranges. Pearson correlation analysis was used to measure the degree to which two variables were related. Statistical significance was considered at $p<0.05$. All analyses were conducted using the GraphPad Prism version 5.00 software for Windows (San Diego, CA, USA).

\section{Results}

\subsection{Analysis of açai aqueous extract}

The total phenolic and flanonoid content of AAE was $118.13 \mathrm{mg}$ GAE/100 g and $9.23 \mathrm{mg} / 100 \mathrm{~g}$ respectively. Antioxidant capacity of AAE, as determined spectrophotometrically through DPPH method, was $6.42 \mu \mathrm{M}$ TEAC/g. The results are presented in the Table 2. Del Pozo-Insfran, Brenes, and Talcott (2004) concluded that anthocyanins were the predominant contributing factor to the antioxidant capacity of açai, which was found to be higher than several berries.

The chromatogram obtained by HPLC of the AAE and an-

\begin{tabular}{|c|c|}
\hline Compounds & Concentration (mg/100 g) \\
\hline Total polyphenols & $118.13 \pm 3.43$ \\
\hline Total flavonoids & $9.23 \pm 0.67$ \\
\hline Total monomeric anthocyanins ${ }^{\mathrm{a}}$ & $6.45 \pm 0.07$ \\
\hline Cyanidin 3-O glucoside ${ }^{b}$ & $0.13 \pm 0.02$ \\
\hline Cyanidin 3-O rutinoside ${ }^{b}$ & $2.57 \pm 0.38$ \\
\hline Antioxidant capacity ( $\mu \mathrm{M}$ TEAC/g) & $6.42 \pm 0.03$ \\
\hline \multicolumn{2}{|c|}{$\begin{array}{l}\text { Values are expressed as means } \pm \text { SEM. All mean values are from trip- } \\
\text { licate determinations. } \\
\text { a Total monomeric anthocyanins measured by the } \mathrm{pH} \text { differential } \\
\text { method. } \\
\text { b Cyanidin } 3-\mathrm{O} \text { glucoside and Cyanidin } 3-\mathrm{O} \text { rutinoside determined } \\
\text { by HPLC-DAD analysis. } \\
\text { TEAC, Trolox equivalent antioxidant capacity. }\end{array}$} \\
\hline
\end{tabular}
thocyanin standard mixture is presented in Fig. 1. 

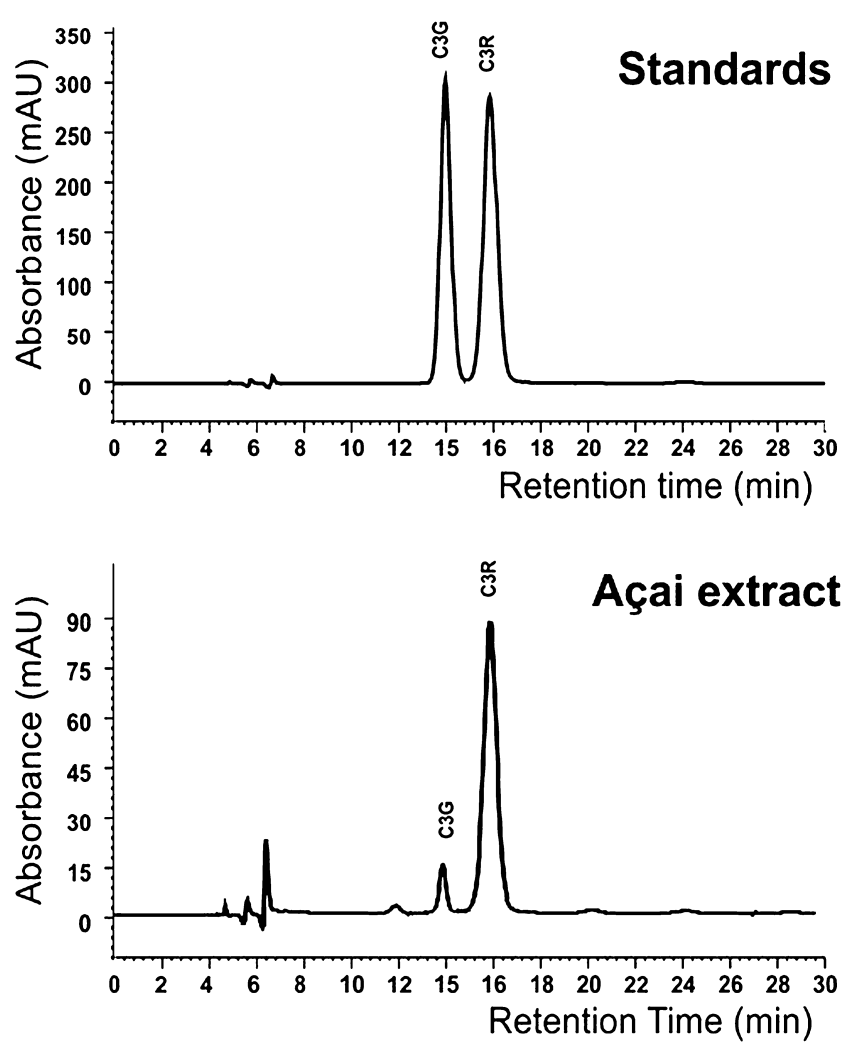

Fig. 1 - HPLC-DAD chromatograms at $520 \mathrm{~nm}$ of açai aqueous extract major anthocyanin compounds. C3G, Cyanidin 3-O glucoside and C3R, Cyanidin 3-O rutinoside.

After identifying cyanidin 3-O-rutinoside and cyanidin 3-Oglucoside, the major anthocyanins in açai by HPLC, we quantified the content of total monomeric anthocyanins by the pH-differential method. The AAE showed total anthocyanin content of $6.45 \mathrm{mg} / 100 \mathrm{~g}$ as shown in Table 2.

\subsection{Effects of AAE on body mass and food intake}

At the end of the experiment, HF and HFA mice exhibited an increase in body weight as shown in Table 3, despite a reduction in food intake. Treatment with AAE for six weeks did not alter the body weight gain or food intake of the HFA group, as compared with the HF animals.
To examine WAT mass, we measured the epididymal, mesenteric, and retroperitoneal fat pad weight. HF mice had a higher fat deposition (mesenteric and retroperitoneal) than $\mathrm{C}$ mice, whereas HFA mice showed a partial reduction in these fat deposits. There were no differences in epididymal fat pad weight between the experimental groups.

\subsection{Effects of AAE on adiponectin production and insulin sensitivity}

To examine whether dietary açai modulated adiponectin production, we measured adiponectin mRNA expression in WAT and serum levels. Compared with the $C$ group, the HF group had lower levels of adiponectin mRNA in WAT and less adiponectin in serum. Administration of AAE significantly upregulated adiponectin gene expression and increased serum levels of this adipokine (Fig. 2). Glucose and insulin levels were markedly increased in the HF group (Table 4). Furthermore, insulin resistance (assessed using the HOMA-IR index) was approximately three-fold higher in the HF group than in the $C$ group. Although AAE treatment did not influence glucose levels, serum insulin levels were partially reduced, with HOMA-IR scores of 8.3 in the HF group and 5.3 in the HFA group. This indicated that AAE improved insulin sensitivity in mice on HFD.

\subsection{Effects of AAE on hepatic steatosis and liver injury}

Mice fed with HFD exhibited hepatomegaly and increased ALT activity, indicating impaired hepatic function (Table 4). Furthermore, the HF group also exhibited an intense accumulation of TG in the liver (Fig. 3F). AAE administration significantly improved these parameters; the HFA group exhibited reduced liver weight, lower ALT activity, and a $44 \%$ decrease in hepatic TG content. AST activity was similar between the experimental groups.

The histological analyses showed a remarkable increase in lipid deposition in the livers of the HF mice (Fig. 3C), characteristic of accentuated micro- and macro-vesicular steatosis, accompanied by an inflammatory cell infiltration. A statistically significant increase in the steatosis score was seen in livers from the HF group, as compared to the $C$ group (Fig. 3E). As shown in Fig. 3D, AAE treatment attenuated hepatic steatosis, as evidenced by a marked decrease in lipid droplets, and it also reduced inflammatory cell infiltration. Furthermore, the

\section{Table 3 - Body composition and food intake in mice fed either a control or high-fat diet treated with açai.}

\begin{tabular}{|c|c|c|c|c|}
\hline \multirow[t]{2}{*}{ Parameter } & \multicolumn{4}{|c|}{ Experimental groups } \\
\hline & C & A & $\mathrm{HF}$ & HFA \\
\hline Initial body weight (g) & $24.71 \pm 0.36$ & $25.19 \pm 0.47$ & $24.73 \pm 0.57$ & $24.86 \pm 0.32$ \\
\hline Final body weight (g) & $50.94 \pm 0.93^{b}$ & $47.03 \pm 1.47^{b}$ & $62.20 \pm 2.48^{\mathrm{a}}$ & $59.69 \pm 1.93^{\mathrm{a}}$ \\
\hline Food intake (g/dia) & $3.78 \pm 0.27^{a}$ & $3.49 \pm 0.28^{\mathrm{a}}$ & $2.85 \pm 0.08^{b}$ & $3.07 \pm 0.13^{b}$ \\
\hline Epididymal fat (g) & $2.19 \pm 0.15$ & $1.57 \pm 0.16$ & $2.50 \pm 0.18$ & $2.41 \pm 0.16$ \\
\hline Mesenteric fat (g) & $0.78 \pm 0.13^{b}$ & $0.75 \pm 0.08^{b}$ & $1.34 \pm 0.10^{\mathrm{a}}$ & $1.10 \pm 0.14^{\mathrm{ab}}$ \\
\hline Retroperitoneal fat (g) & $0.70 \pm 0.11^{b}$ & $0.46 \pm 0.09^{b}$ & $1.35 \pm 0.21^{\mathrm{a}}$ & $1.17 \pm 0.10^{\mathrm{ab}}$ \\
\hline
\end{tabular}

Values are expressed as means $\pm \operatorname{SEM}(n=8)$. Within a row, significantly different values are marked with different superscript letters. 
A

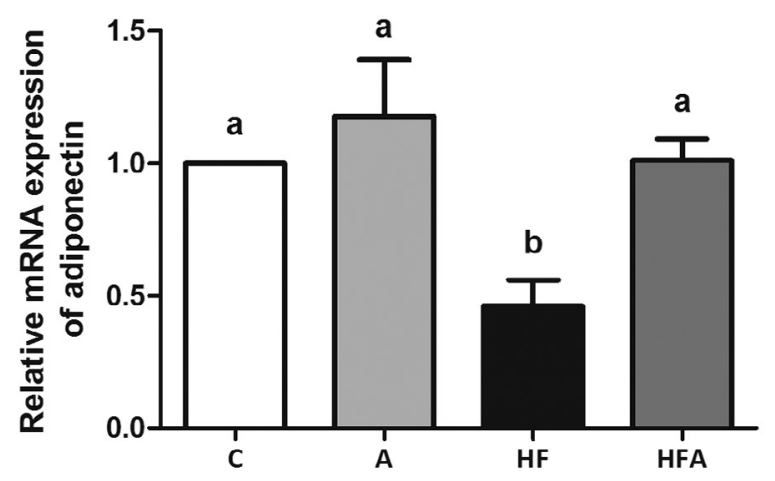

C

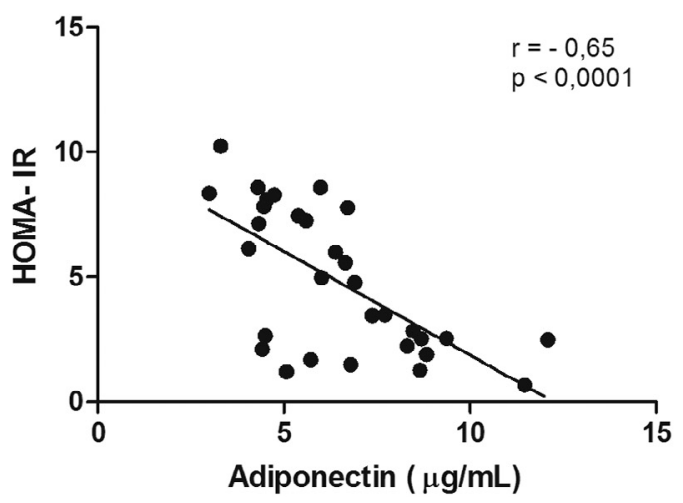

B

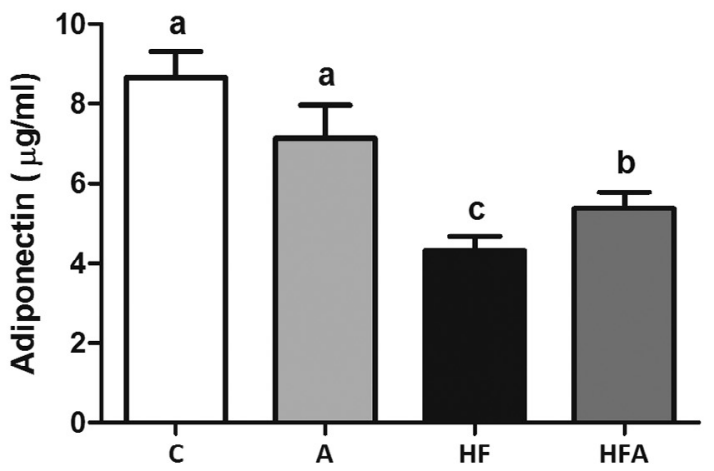

D

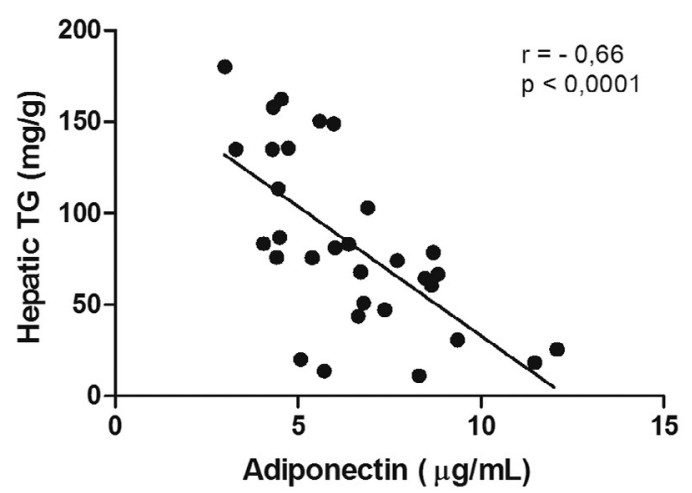

Fig. 2 - Gene expression levels in epididymal white adipose tissue (A) and serum concentrations of adiponectin (B) in mice fed a control or high-fat diet treated with açai. Adiponectin mRNA expressions were measured by real-time PCR relative to 18S rRNA, and normalized by Control group. Serum levels of adiponectin were measured by ELISA. Values are expressed as means $\pm \operatorname{SEM}(n=6)$. Significantly different values are marked with different superscript letters. Serum adiponectin levels inversely correlated with homeostasis model assessment of insulin resistance (HOMA-IR) (Pearson $r=-0.65, p<0.0001$ ) (C) and hepatic triacylglycerol content (Pearson $\mathrm{r}=-0.66, \mathrm{p}<0.0001)(\mathrm{D})$.

hepatic steatosis score was lower in the HFA group than in the HF group. These histological data were consistent with the reduced hepatic TG content and ALT serum levels in the HFA group, indicating that $\mathrm{AAE}$ improved hepatic morphology and function. Additionally, negative correlations were found between serum adiponectin and the HOMA-IR index $(r=-0.65, p<0.0001)$, and between serum adiponectin and the liver TG content $(\mathrm{r}=-0.66, p<0.0001)$ (Fig. 2).

Table 4 - Serum and hepatic biochemical parameters in mice fed either a control or high-fat diet treated with açai.

\begin{tabular}{|c|c|c|c|c|}
\hline \multirow[t]{2}{*}{ Parameter } & \multicolumn{4}{|c|}{ Experimental groups } \\
\hline & C & A & $\mathrm{HF}$ & HFA \\
\hline \multicolumn{5}{|l|}{ Serum } \\
\hline Glucose (mmol/L) & $8.78 \pm 0.35^{b}$ & $8.73 \pm 0.85^{b}$ & $12.70 \pm 0.11^{\mathrm{a}}$ & $11.71 \pm 0.60^{\mathrm{a}}$ \\
\hline Insulin $(\mathrm{pmol} / \mathrm{L})$ & $51.90 \pm 9.91^{b}$ & $35.22 \pm 7.57^{b}$ & $102.7 \pm 6.07^{a}$ & $79.85 \pm 8.95^{\mathrm{ab}}$ \\
\hline HOMA (IR) & $2.84 \pm 0.48^{c}$ & $2.10 \pm 0.61^{c}$ & $8.34 \pm 0.46^{a}$ & $5.91 \pm 0.64^{b}$ \\
\hline $\operatorname{ALT}(\mathrm{U} / \mathrm{L})$ & $21.83 \pm 3.11^{\mathrm{b}}$ & $23.70 \pm 4.10^{\mathrm{b}}$ & $43.36 \pm 6.56^{\mathrm{a}}$ & $24.43 \pm 2.98^{b}$ \\
\hline $\operatorname{AST}^{1}(\mathrm{U} / \mathrm{L})$ & $83.61 / 76.5-97.8$ & $85.67 / 77.1-102.2$ & $87.75 / 74.2-109.9$ & $85.15 / 70.3-103.8$ \\
\hline Liver weight (g) & $2.17 \pm 0.13^{b}$ & $1.91 \pm 0.04^{\mathrm{b}}$ & $4.19 \pm 0.35^{\mathrm{a}}$ & $3.15 \pm 0.35^{b}$ \\
\hline
\end{tabular}

Values are expressed as means \pm SEM or ${ }^{1}$ median and interquartile range $(n=8)$. Within a row, significantly different values are marked with different superscript letters. 

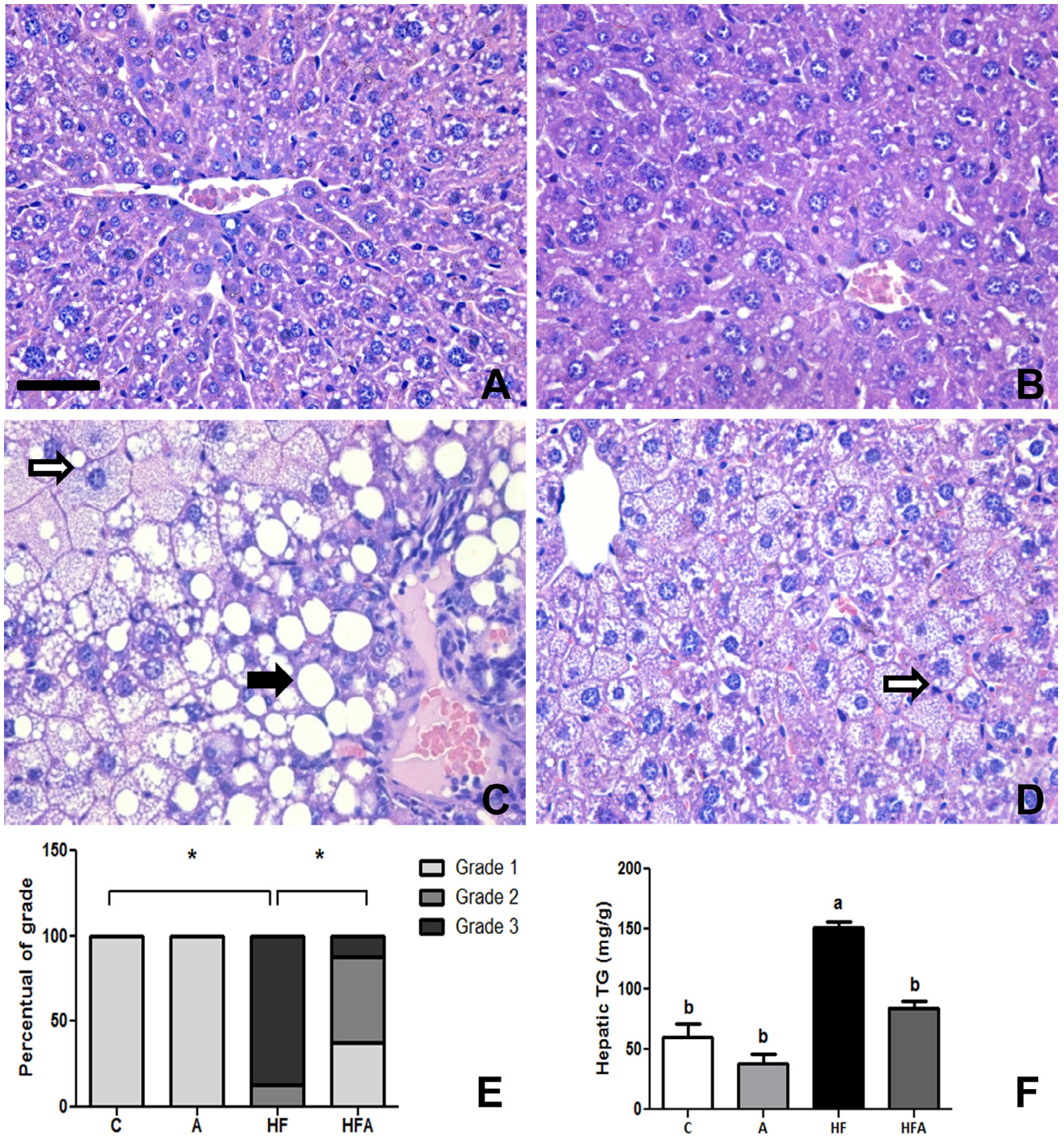

Fig. 3 - Representative hematoxylin and eosin-stained histological sections of livers from mice fed a control or high-fat diet treated with açai. Hepatocytes abnormalities were not observed in the C group (A) and CA group (B). Note severe steatosis in the HF group (C) mixed microvesicular (white arrow) and macrovesicular (black arrow) steatosis and the presence of inflammatory infiltrate. Açai treatment attenuated fat accumulation in hepatocytes as shown by the lower content of fat droplets and the absence of macrovesicular steatosis (D). The images were photographed at $400 \times$ magnification. Scale bar $=50 \mu \mathrm{m}$. Grade of liver steatosis (E) and hepatic triacylglycerol content (F) of mice fed a control or high-fat diet treated with açai. Asterisk (*) indicates significant difference between two groups.

3.5. Effects of AAE on the expression of genes related to fatty acid biosynthesis and oxidation in the liver

We next investigated whether AAE administration modulated the expression of adiponectin signaling-related genes involved in lipogenesis and fatty acid oxidation. In HF animals, SREBP-1c expression increased by approximately two-fold, as compared with the $\mathrm{C}$ animals, and the levels of FAS and ACC1 mRNA also increased. In contrast, the levels of SREBP-1c and FAS mRNA in the HFA group did not differ significantly from 


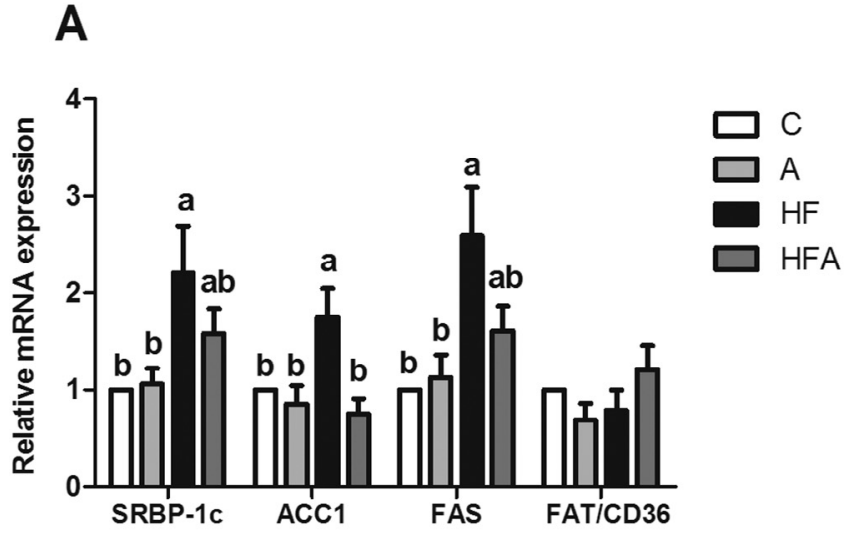

B

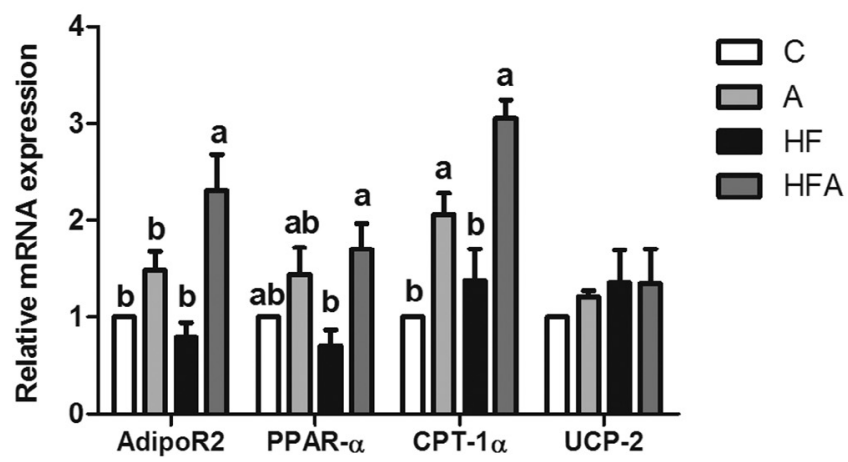

Fig. 4 - Relative expression of mRNA of genes involved in hepatic lipid metabolic pathways in mice fed a control or high-fat diet treated with açai. Fatty acid uptake and lipogenic genes (A), fatty acid oxidation genes (B) relative to $18 \mathrm{~S}$ rRNA, and normalized by Control group. Values are expressed as means $\pm \operatorname{SEM}(n=6)$. Significantly different values are marked with different superscript letters.

those in the C group, and ACC1 mRNA expression was significantly reduced in the HFA group, in comparison with the HF group (Fig. 4A).

As shown in Fig. 3B, the hepatic expression of adiponectin receptor (AdipoR2) mRNA increased more than two-fold in the HFA group. We also found that the expression levels of PPAR- $\alpha$ and its target gene, carnitine palmitoyltransferase (CPT- $1 \alpha)$, were higher in this group than in the HF group.

We also determined the mRNA expression of fatty acid translocase (FAT), which is involved in fatty acid uptake, and uncoupling protein 2 (UCP-2), which is predominantly expressed in the liver, because both of these proteins can be involved in hepatic lipid accumulation (Lin et al., 2000; Miquilena-Colina et al., 2011). There was no difference in the expression of these genes between the experimental groups (Fig. 4A and B).

\section{Discussion}

The present study highlights the potential benefits of açai, a source of dietary anthocyanins on alleviating hepatic steato- sis in mice. Administration of AAE was associated with increased circulating adiponectin levels, which has a causal role in improving insulin sensitivity, up-regulation of key transcriptional regulators involved in fatty-acid oxidation, and a decline in liver triglyceride accumulation. The açai dose used in this study was selected on the basis of an average daily intake of approximately $200 \mathrm{~g}$ by a $70 \mathrm{~kg}$ individual, corresponding to approximately $3 \mathrm{~g} / \mathrm{kg}$ body weight. This dose had already been shown to have beneficial effects on insulin resistance in overweight individuals (Udani et al., 2011) and had been used in experimental models (Ribeiro et al., 2010).

Anthocyanins are the predominant phytochemicals present in açai pulp. Previous studies have found cyanidin 3-rutinoside as the major anthocyanin in açai, followed by cyanidin 3-glucoside (Lichtenthaler et al., 2005; Vera de Rosso et al., 2008). In our study, the aqueous extract of açai was obtained from a commercial pulp, which typically has lower levels of anthocyanins than fresh fruit. However, açai fruit is highly perishable, thus, is predominantly consumed and marketed as frozen pulps, and other industrial products, which go through several processing steps such as pasteurization, freezing and dilution (Pacheco-Palencia, Hawken, \& Talcott, 2007).

Many studies have reported on the actions of anthocyanin on metabolism, especially on the regulation of lipid metabolism and inflammation, however, in most cases, the doses used are impractical to be obtained only through a normal diet. Therefore, we conduct investigations using similar doses to the estimated physiological levels of consumption. Although estimated human dietary intake of flavonoid varies widely among studies (Chun, Chung, \& Song, 2007), the overall daily intake of total anthocyanins was estimated as $12.5 \mathrm{mg} /$ person (Wu et al., 2006), which corresponds to approximately $0.2 \mathrm{mg} / \mathrm{kg}$ body weight in adults. In this study, considering the amount of anthocyanins present in $\mathrm{AAE}$, the average intake was also approximately $0.2 \mathrm{mg} / \mathrm{kg}$ body weight in AAE treated mice. Thus, anthocyanin concentrations used can be considered a dose, which can be easily consumed with the diet.

In our model, the HFD promoted increased weight gain, adiposity, insulin resistance, and hepatic steatosis, as well as alterations in adiponectin production. It is well established that this type of diet can lead to such alterations in experimental models and in humans (Feskens et al., 1995; Peng, Rideout, Rakita, Lee, \& Murr, 2012). Insulin resistance induced by HFD is related to adiponectin depletion. Adiponectin is an adipocytederived hormone with well-established anti-inflammatory and insulin-sensitizing properties. The mRNA expression and serum level of adiponectin are significantly reduced in obese/diabetic mice and humans, and this change precedes the associated decrease in insulin sensitivity (Hu, Liang, \& Spiegelman, 1996; Stefan et al., 2002). Furthermore, physiological doses of adiponectin improved insulin resistance in mouse models of obesity and type 2 diabetes (Yamauchi et al., 2001). The present study demonstrated that $\mathrm{AAE}$ attenuated insulin resistance and alleviated the HFD-induced reduction in adiponectin expression in fat tissue and adiponectin levels in serum. These effects occurred independently of the size of the animal's body fat stores, because only a subtle modification of body composition was observed. The HOMA-IR showed a negative correlation with the concentration of circulating adiponectin. Taken together, these data suggested that the AAE-related improvement 
in insulin sensitivity açai was mediated by adiponectin. Previous data showed that C3G stimulates the expression and secretion of adiponectin in adipocytes of mice and humans and increases adiponectin expression and insulin sensitivity in both diet-induced and genetic animal models of type 2 diabetes. In a clinical study, the daily intake of $320 \mathrm{mg}$ of purified anthocyanins, increased levels of serum adiponectin in diabetic individuals. The probable mechanism by which C3G increases adiponectin expression involves changes in the acetylation of transcription factor forkhead box 01 (Foxo1), which regulates adiponectin transcription (Guo et al., 2012; Liu, Li, Zhang, Sun, \& Xia, 2014).

We demonstrated that AAE treatment efficiently attenuated HFD-induced hepatic steatosis, as evidenced by the reduction in TG content and by histological analyses. This effect contributed to reduced liver weight and serum ALT levels in treated mice. The increased circulating adiponectin levels in açai the HFA mice could also provide an explanation for the reduced hepatic TG content, given that hypoadiponectinemia is often associated with higher grades of hepatic steatosis and has been considered a typical feature of NAFLD (Hui et al., 2004). Indeed, adiponectin knockout mice exhibited permanent hepatic steatosis (Zhou et al., 2008). Our data are consistent with these observations, since hepatic TG content and adiponectin serum levels were found to be inversely correlated.

The mechanisms by which adiponectin has been shown to reduce hepatic lipid accumulation include sensitization of hepatic adiponectin receptor (AdipoR2), which activates the nuclear receptor PPAR- $\alpha$, a ligand-activated transcription factor that is considered to be one of the main regulators of fatty acid oxidation (Yamauchi et al., 2003). PPAR- $\alpha$ activation upregulates $\mathrm{CPT}-1 \alpha$, stimulates $\beta$-oxidation, reduces lipid biosynthesis, and therefore prevents excessive TG accumulation (Yamauchi \& Kadowaki, 2008). Açai treatment increased the expression of AdipoR2, PPAR- $\alpha$, and CPT- $1 \alpha$, suggesting a possible increase in fatty acid oxidation through adiponectininduced PPAR- $\alpha$ up-regulation.

Moreover, it has been reported that isolated anthocyanins and anthocyanin-rich extracts enhances both mRNA levels (Seymour et al., 2008) and the activity of PPAR- $\alpha$ in the liver. Cyanidin induces transactivation activity of PPAR- $\alpha$ in a reporter gene assay and also bound directly to PPAR- $\alpha$ (Jia et al., 2013). Thus, anthocyanins likely act as a PPAR- $\alpha$ agonist.

In addition, AAE inhibited hepatic lipogenesis pathways, given that it produced a small but significant reduction in the expression of SREBP-1C and FAS, and down-regulated ACC1 mRNA levels. These findings are consistent with previous reports showing beneficial effects of dietary anthocyanins and other polyphenols, particularly in the reduction of steatosis and liver damage through inhibition of lipogenesis and promoting lipolysis. (Shi et al., 2014; Valenti et al., 2013; Wu et al., 2013). Owing to these effects, anthocyanin has been explored as a potential nutritional therapy for a large number of diseases (Xia \& Weng, 2010). Although our findings reflect those obtained with isolated anthocyanin, suggesting that the smaller dose of anthocyanins in AAE retained biological effects and may be the active constituent toward these metabolic effects, we cannot exclude the benefits of other phytochemicals in AAE, such as pro-anthocyanidins, catechins, epicatechins, orientin, luteolin, lignans, phenolic acids such as gallic acid and ferulic acid, and resveratrol is also present at low concentrations (Pacheco-Palencia, Duncan, \& Talcott, 2009; Schauss, Wu, Prior, Ou, Patel et al., 2006). AAE may therefore produce more pronounced effects than each isolated compound, as crude extracts can exert additive or synergistic effects due to the presence of several phytochemicals (Liu, 2004).

In conclusion, the present study demonstrated that açai, has a protective effect against NAFLD and provided new perspectives in the understanding of the possible mechanisms involved. Our data supported the idea that increases in adiponectin expression and circulating levels likely represents a major mechanism whereby açai administration alleviated HFD-induced NAFLD in mice by improving insulin sensitivity and modulating pathways related to hepatic lipid metabolism. These findings indicate that intake of anthocyanins from dietary sources at physiological doses may have important implications for preventing metabolic disorders.

\section{Conflict of interest}

All authors declare no competing interests.

\section{Acknowledgements}

This work was supported by FAPEMIG Foundation (Research Support Foundation of Minas Gerais State) - Process CDS-APQ01340-11 and CNPq (National Council for Scientific and Technological Development) - Process no. 475247/2011-6.

\section{REFERENCES}

Albano, E., Mottaran, E., Vidali, M., Reale, E., Saksena, S., Occhino, G., Burt, A. D., \& Day, C. P. (2005). Immune response towards lipid peroxidation products as a predictor of progression of non-alcoholic fatty liver disease to advanced fibrosis. Gut, 54(7), 987-993.

Brand-Williams, W., Cuvelier, M. E., \& Berset, C. (1995). Use of a free radical method to evaluate antioxidant activity. LWT-Food Science and Technology, 28(1), 25-30.

Browning, J. D., \& Horton, J. D. (2004). Molecular mediators of hepatic steatosis and liver injury. The Journal of Clinical Investigation, 114(2), 147-152.

Chun, O. K., Chung, S. J., \& Song, W. O. (2007). Estimated dietary flavonoid intake and major food sources of U.S. adults. The Journal of Nutrition, 137(5), 1244-1252.

de Souza, M. O., Silva, M., Silva, M. E., Oliveira Rde, P., \& Pedrosa, M. L. (2010). Diet supplementation with acai (Euterpe oleracea Mart.) pulp improves biomarkers of oxidative stress and the serum lipid profile in rats. Nutrition (Burbank, Los Angeles County, Calif.), 26(7-8), 804-810.

de Souza, M. O., Souza, E. S. L., de Brito Magalhaes, C. L., de Figueiredo, B. B., Costa, D. C., Silva, M. E., \& Pedrosa, M. L. (2012). The hypocholesterolemic activity of acai (Euterpe oleracea Mart.) is mediated by the enhanced expression of the ATP-binding cassette, subfamily G transporters 5 and 8 and low-density lipoprotein receptor genes in the rat. Nutrition Research (New York, N.Y.), 32(12), 976-984. 
Del Pozo-Insfran, D., Brenes, C. H., \& Talcott, S. T. (2004) Phytochemical composition and pigment stability of Acai (Euterpe oleracea Mart.). Journal of Agricultural and Food Chemistry, 52(6), 1539-1545.

Dragano, N. R., Marques, A., Cintra, D. E., Solon, C., Morari, J., Leite-Legatti, A. V., Velloso, L. A., \& Marostica-Junior, M. R. (2013). Freeze-dried jaboticaba peel powder improves insulin sensitivity in high-fat-fed mice. [Research Support, Non-U.S. Gov't]. The British Journal of Nutrition, 110(3), 447-455.

Farrell, G. C., \& Larter, C. Z. (2006). Nonalcoholic fatty liver disease: From steatosis to cirrhosis. Hepatology (Baltimore, Md.), 43(S1), S99-S112.

Fernandes, I., Faria, A., Calhau, C., de Freitas, V., \& Mateus, N. (2014). Bioavailability of anthocyanins and derivatives. Journal of Functional Foods, 7(0), 54-66.

Feskens, E. J., Virtanen, S. M., Rasanen, L., Tuomilehto, J., Stengard, J., Pekkanen, J., Nissinen, A., \& Kromhout, D. (1995). Dietary factors determining diabetes and impaired glucose tolerance. A 20-year follow-up of the Finnish and Dutch cohorts of the Seven Countries Study. Diabetes Care, 18(8), 1104-1112.

Folch, J., Lees, M., \& Sloane Stanley, G. H. (1957). A simple method for the isolation and purification of total lipides from animal tissues. The Journal of Biological Chemistry, 226(1), 497-509.

Gallori, S., Bilia, A. R., Bergonzi, M. C., Barbosa, W. L. R., \& Vincieri, F. F. (2004). Polyphenolic constituents of fruit pulp of Euterpe oleracea Mart. (Açai palm). Chromatographia, 59(11-12), 739743.

George, S., Brat, P., Alter, P., \& Amiot, M. J. (2005). Rapid determination of polyphenols and vitamin $C$ in plant-derived products. Journal of Agricultural and Food Chemistry, 53(5), 13701373.

Guerra, J. F., Magalhaes, C. L., Costa, D. C., Silva, M. E., \& Pedrosa, M. L. (2011). Dietary acai modulates ROS production by neutrophils and gene expression of liver antioxidant enzymes in rats. Journal of Clinical Biochemistry and Nutrition, 49(3), 188194.

Guo, H., Xia, M., Zou, T., Ling, W., Zhong, R., \& Zhang, W. (2012). Cyanidin 3-glucoside attenuates obesity-associated insulin resistance and hepatic steatosis in high-fat diet-fed and db/ $\mathrm{db}$ mice via the transcription factor FoxO1. The Journal of Nutritional Biochemistry, 23(4), 349-360.

Hossain, M. A., \& Rahman, S. M. M. (2011). Total phenolics, flavonoids and antioxidant activity of tropical fruit pineapple. Food Research International, 44(3), 672-676.

Hu, E., Liang, P., \& Spiegelman, B. M. (1996). AdipoQ is a novel adipose-specific gene dysregulated in obesity. The Journal of Biological Chemistry, 271(18), 10697-10703.

Hui, J. M., Hodge, A., Farrell, G. C., Kench, J. G., Kriketos, A., \& George, J. (2004). Beyond insulin resistance in NASH: TNFalpha or adiponectin? Hepatology (Baltimore, Md.), 40(1), 46-54.

Hwang, Y. P., Choi, J. H., Han, E. H., Kim, H. G., Wee, J.-H., Jung, K. O., Jung, K. H., Kwon, K.-I., Jeong, T. C., Chung, Y. C., \& Jeong, H. G. (2011). Purple sweet potato anthocyanins attenuate hepatic lipid accumulation through activating adenosine monophosphate-activated protein kinase in human HepG2 cells and obese mice. Nutrition Research (New York, N.Y.), 31(12), 896-906.

Jia, Y., Kim, J. Y., Jun, H. J., Kim, S. J., Lee, J. H., Hoang, M. H., Kim, H. S., Chang, H. I., Hwang, K. Y., Um, S. J., \& Lee, S. J. (2013). Cyanidin is an agonistic ligand for peroxisome proliferatoractivated receptor-alpha reducing hepatic lipid. Biochimica et Biophysica Acta, 1831(4), 698-708.

Lichtenthaler, R., Rodrigues, R. B., Maia, J. G., Papagiannopoulos, M., Fabricius, H., \& Marx, F. (2005). Total oxidant scavenging capacities of Euterpe oleracea Mart. (Acai) fruits. International Journal of Food Sciences and Nutrition, 56(1), 53-64.
Lin, H. Z., Yang, S. Q., Chuckaree, C., Kuhajda, F., Ronnet, G., \& Diehl, A. M. (2000). Metformin reverses fatty liver disease in obese, leptin-deficient mice. Nature Medicine, 6(9), 998-1003.

Liu, R. H. (2004). Potential synergy of phytochemicals in cancer prevention: Mechanism of action. The Journal of Nutrition, 134(12 Suppl.), 3479s-3485s.

Liu, Y., Li, D., Zhang, Y., Sun, R., \& Xia, M. (2014). Anthocyanin increases adiponectin secretion and protects against diabetes-related endothelial dysfunction. American Journal of Physiology. Endocrinology and Metabolism, 306(8), E975-E988.

Marcason, W. (2009). What is the acai berry and are there health benefits? Journal of the American Dietetic Association, 109(11), 1968.

Marchesini, G., Brizi, M., Bianchi, G., Tomassetti, S., Bugianesi, E., Lenzi, M., McCullough, A. J., Natale, S., Forlani, G., \& Melchionda, N. (2001). Nonalcoholic fatty liver disease: A feature of the metabolic syndrome. Diabetes, 50(8), 1844-1850.

Matthews, D. R., Hosker, J. P., Rudenski, A. S., Naylor, B. A., Treacher, D. F., \& Turner, R. C. (1985). Homeostasis model assessment: Insulin resistance and beta-cell function from fasting plasma glucose and insulin concentrations in man. Diabetologia, 28(7), 412-419.

Miquilena-Colina, M. E., Lima-Cabello, E., Sanchez-Campos, S., Garcia-Mediavilla, M. V., Fernandez-Bermejo, M., LozanoRodriguez, T., Vargas-Castrillon, J., Buque, X., Ochoa, B., Aspichueta, P., Gonzalez-Gallego, J., \& Garcia-Monzon, C. (2011). Hepatic fatty acid translocase CD36 upregulation is associated with insulin resistance, hyperinsulinaemia and increased steatosis in non-alcoholic steatohepatitis and chronic hepatitis C. Gut, 60(10), 1394-1402.

Neuschwander-Tetri, B. A., \& Caldwell, S. H. (2003). Nonalcoholic steatohepatitis: Summary of an AASLD Single Topic Conference. Hepatology (Baltimore, Md.), 37(5), 1202-1219.

Normas Analíticas do Instituto Adolfo Lutz (2008). Métodos Químicos e Físicos para Análise de Alimentos (p. 1020). São Paulo: Instituto Adolfo Lutz.

Ong, J. P., \& Younossi, Z. M. (2007). Epidemiology and natural history of NAFLD and NASH. Clinics in Liver Disease, 11(1), 1-16, vii.

Pacheco-Palencia, L. A., Hawken, P., \& Talcott, S. T. (2007). Phytochemical, antioxidant and pigment stability of açai (Euterpe oleracea Mart.) as affected by clarification, ascorbic acid fortification and storage. Food Research International, 40(5), 620-628.

Pacheco-Palencia, L. A., Duncan, C. E., \& Talcott, S. T. (2009). Phytochemical composition and thermal stability of two commercial acai species, Euterpe oleracea and Euterpe precatoria. Food Chemistry, 115(4), 1199-1205.

Peng, Y., Rideout, D., Rakita, S., Lee, J., \& Murr, M. (2012). Dietinduced obesity associated with steatosis, oxidative stress, and inflammation in liver. Surgery for Obesity and Related Diseases, 8(1), 73-81.

Postic, C., \& Girard, J. (2008). The role of the lipogenic pathway in the development of hepatic steatosis. Diabetes \& Metabolism, 34(6 Pt. 2), 643-648.

Reeves, P. G., Nielsen, F. H., \& Fahey, G. C., Jr. (1993). AIN-93 purified diets for laboratory rodents: Final report of the American Institute of Nutrition ad hoc writing committee on the reformulation of the AIN-76A rodent diet. The Journal of Nutrition, 123(11), 1939-1951.

Ribeiro, J. C., Antunes, L. M., Aissa, A. F., Darin, J. D., De Rosso, V. V., Mercadante, A. Z., \& Bianchi Mde, L. (2010). Evaluation of the genotoxic and antigenotoxic effects after acute and subacute treatments with acai pulp (Euterpe oleracea Mart.) on mice using the erythrocytes micronucleus test and the comet assay. Mutation Research, 695(1-2), 22-28. 
Schauss, A. G., Wu, X., Prior, R. L., Ou, B., Huang, D., Owens, J., Agarwal, A., Jensen, G. S., Hart, A. N., \& Shanbrom, E. (2006). Antioxidant capacity and other bioactivities of the freezedried Amazonian palm berry, Euterpe oleraceae mart. (acai). Journal of Agricultural and Food Chemistry, 54(22), 8604-8610.

Schauss, A. G., Wu, X., Prior, R. L., Ou, B., Patel, D., Huang, D., \& Kababick, J. P. (2006). Phytochemical and nutrient composition of the freeze-dried Amazonian palm berry, Euterpe oleraceae mart. (acai). Journal of Agricultural and Food Chemistry, 54(22), 8598-8603.

Seymour, E. M., Singer, A. A., Kirakosyan, A., Urcuyo-Llanes, D. E., Kaufman, P. B., \& Bolling, S. F. (2008). Altered hyperlipidemia, hepatic steatosis, and hepatic peroxisome proliferatoractivated receptors in rats with intake of tart cherry. Journal of Medicinal Food, 11(2), 252-259.

Shi, L., Liu, Y., Tan, D., Yan, T., Song, D., Hou, M., \& Meng, X. (2014). Blueberry anthocyanins ameliorate cyclophosphamideinduced liver damage in rats by reducing inflammation and apoptosis. Journal of Functional Foods, 11, 71-81.

Shimomura, I., Bashmakov, Y., \& Horton, J. D. (1999). Increased levels of nuclear SREBP-1c associated with fatty livers in two mouse models of diabetes mellitus. The Journal of Biological Chemistry, 274(42), 30028-30032.

Stefan, N., Vozarova, B., Funahashi, T., Matsuzawa, Y., Weyer, C., Lindsay, R. S., Youngren, J. F., Havel, P. J., Pratley, R. E., Bogardus, C., \& Tataranni, P. A. (2002). Plasma adiponectin concentration is associated with skeletal muscle insulin receptor tyrosine phosphorylation, and low plasma concentration precedes a decrease in whole-body insulin sensitivity in humans. Diabetes, 51(6), 1884-1888.

Stienstra, R., Duval, C., Muller, M., \& Kersten, S. (2007). PPARs, obesity, and inflammation. PPAR Research, 2007, 95974.

Udani, J. K., Singh, B. B., Singh, V. J., \& Barrett, M. L. (2011). Effects of Acai (Euterpe oleracea Mart.) berry preparation on metabolic parameters in a healthy overweight population: A pilot study. Nutrition Journal, 10, 45.

Valenti, L., Riso, P., Mazzocchi, A., Porrini, M., Fargion, S., \& Agostoni, C. (2013). Dietary anthocyanins as nutritional therapy for nonalcoholic fatty liver disease. Oxidative Medicine and Cellular Longevity, 2013, 145421.

Vera de Rosso, V., Hillebrand, S., Cuevas Montilla, E., Bobbio, F. O., Winterhalter, P., \& Mercadante, A. Z. (2008). Determination of anthocyanins from acerola (Malpighia emarginata DC.) and açai (Euterpe oleracea Mart.) by HPLC-PDA-MS/MS. Journal of Food Composition and Analysis, 21(4), 291-299.

Wang, D., Wei, Y., \& Pagliassotti, M. J. (2006). Saturated fatty acids promote endoplasmic reticulum stress and liver injury in rats with hepatic steatosis. Endocrinology, 147(2), 943-951.
Wu, C.-H., Chen, S.-C., Ou, T.-T., Chyau, C.-C., Chang, Y.-C., \& Wang, C.-J. (2013). Mulberry leaf polyphenol extracts reduced hepatic lipid accumulation involving regulation of adenosine monophosphate activated protein kinase and lipogenic enzymes. Journal of Functional Foods, 5(4), 1620-1632.

Wu, X., Beecher, G. R., Holden, J. M., Haytowitz, D. B., Gebhardt, S. E., \& Prior, R. L. (2006). Concentrations of anthocyanins in common foods in the United States and estimation of normal consumption. Journal of Agricultural and Food Chemistry, 54(11), 4069-4075.

Xia, X., \& Weng, J. (2010). Targeting metabolic syndrome: Candidate natural agents. Journal of Diabetes, 2(4), 243-249.

Xie, C., Kang, J., Burris, R., Ferguson, M. E., Schauss, A. G., Nagarajan, S., \& Wu, X. (2011). Acai juice attenuates atherosclerosis in ApoE deficient mice through antioxidant and anti-inflammatory activities. Atherosclerosis, 216(2), 327333.

Xu, A., Wang, Y., Keshaw, H., Xu, L. Y., Lam, K. S., \& Cooper, G. J. (2003). The fat-derived hormone adiponectin alleviates alcoholic and nonalcoholic fatty liver diseases in mice. The Journal of Clinical Investigation, 112(1), 91-100.

Yamauchi, T., \& Kadowaki, T. (2008). Physiological and pathophysiological roles of adiponectin and adiponectin receptors in the integrated regulation of metabolic and cardiovascular diseases. International Journal of Obesity (2005), 32(Suppl. 7), S13-S18.

Yamauchi, T., Kamon, J., Ito, Y., Tsuchida, A., Yokomizo, T., Kita, S., Sugiyama, T., Miyagishi, M., Hara, K., Tsunoda, M., Murakami, K., Ohteki, T., Uchida, S., Takekawa, S., Waki, H., Tsuno, N. H., Shibata, Y., Terauchi, Y., Froguel, P., Tobe, K., Koyasu, S., Taira, K., Kitamura, T., Shimizu, T., Nagai, R., \& Kadowaki, T. (2003). Cloning of adiponectin receptors that mediate antidiabetic metabolic effects. Nature, 423(6941), 762769.

Yamauchi, T., Kamon, J., Waki, H., Terauchi, Y., Kubota, N., Hara, K., Mori, Y., Ide, T., Murakami, K., Tsuboyama-Kasaoka, N., Ezaki, O., Akanuma, Y., Gavrilova, O., Vinson, C., Reitman, M. L., Kagechika, H., Shudo, K., Yoda, M., Nakano, Y., Tobe, K., Nagai, R., Kimura, S., Tomita, M., Froguel, P., \& Kadowaki, T. (2001). The fat-derived hormone adiponectin reverses insulin resistance associated with both lipoatrophy and obesity. Nature Medicine, 7(8), 941-946.

Zhou, M., Xu, A., Tam, P. K., Lam, K. S., Chan, L., Hoo, R. L., Liu, J., Chow, K. H., \& Wang, Y. (2008). Mitochondrial dysfunction contributes to the increased vulnerabilities of adiponectin knockout mice to liver injury. Hepatology (Baltimore, Md.), 48(4), 1087-1096. 